\title{
The Fertility Regulation Group of the Cochrane Collaboration
}

\author{
Susan Quilliam
}

Freelance Writer, Broadcaster and Agony Aunt, Cambridge, UK

\section{Correspondence to}

Ms Susan Quilliam;

susan@susanquilliam.com

Received 15 May 2012

Accepted 15 May 2012
Who are you?

The Fertility Regulation Group (http:// www.fertility-regulation.org) addresses the process by which people regulate their fertility, family size and spacing of births.

\section{How did you start?}

The Cochrane Collaboration itself (http://www.cochrane.org) was established in 1993 as an international network of more than 28000 dedicated individuals with an interest in fertility and health care from over 100 countries. The Fertility Regulation Group registered with the Collaboration in 1997 and the first Editorial Board Meeting was held in Amsterdam in that year.

\section{What's your mission?}

The Cochrane Collaboration's vision is that health care decision-making throughout the world will be informed by high-quality, timely research evidence. The Fertility Regulation Group's specific mission is to apply that vision to fertility issues (i.e. contraception and unwanted pregnancy).

\section{What services do you offer?}

We work together with other Cochrane Groups (of which there are more than 50) to help health care providers, policymakers and the public (including patients, their advocates and caregivers) make well-informed decisions about health care, based on the best available research evidence. In particular, we prepare, update and promote the accessibility of Cochrane Reviews. To date more than 5000 reviews have been published online in The Cochrane Library (http:// www.cochrane.org-cochrane-reviews).

Review topics have included:

- The effectiveness and safety of fertility-regulating methods; this includes drugs, devices, sterilisation, natural family planning, breastfeeding and termination of unwanted pregnancy
- Contraception and therapeutic abortion (click on 'Gynaecology' left grey panel)

- The delivery of fertility services (its effectiveness, accessibility and acceptability)

- How people obtain and use fertility information

- How people make and implement choices about fertility regulation and preserve their reproductive health

- Issues relating to collaborative decision making and policy development processes.

Our reviews are important as they are used as the best evidence in clinical guidance for professionals worldwide. To date they have been used in the USA by the American College of Obstetricians and Gynecologists, in the UK by the Faculty of Sexual and Reproductive Healthcare of the Royal College of Obstetricians and Gynaecologists, as well as in continental Europe and other parts of the world. Our reviews are incorporated into and support World Health Organization recommendations on safe abortion and family planning.

What's been your biggest triumph over the years?

We are particularly proud of one particular review on copper intrauterine devices that formed the basis of an International Organization for Standardization (ISO) standard. But we have had many triumphs, and every day, consumers, patients, professionals, authorities and other interested people tell us how much they appreciate our work.

\section{What's your biggest worry?}

Funding. These are challenging times financially for many organisations, and the Cochrane Collaboration is totally independent and takes no commercial or conflicted funding for its work. 
What are your most exciting plans and biggest hopes for the future?

Regular updating of our reviews is a challenging but exciting task; our aim is always to guarantee our readers a continuing, up-to-date information source on fertility regulation.

What do you want to say to Journal readers?

We'd like to ask them to get involved. In particular, we are looking for volunteers who are keen to develop and to update systematic reviews in the field of fertility regulation.

"Ask not what the Fertility Regulation Group can do for you; ask what you can do for the Fertility Regulation Group.” (J F Kennedy adapted)

\section{How can Journal readers and their patients} contact you?

Journal readers and their patients can contact either our Managing Editor, Anja Helmerhorst or our Co-ordinating Editor, Frans M Helmerhorst (see Further Information).
Competing interests None.

Provenance and peer review Commissioned; internally peer reviewed.

Editor's note This article is one in a series of occasional articles on key health organisations worldwide.

The Journal would be pleased to hear from other organisations, particularly those based outside the UK, which would like to be similarly profiled.

\begin{tabular}{|c|c|}
\hline & FURTHER INFORMATION \\
\hline Who: & $\begin{array}{l}\text { The Fertility Regulation Group of } \\
\text { the Cochrane Collaboration }\end{array}$ \\
\hline Where: & $\begin{array}{l}\text { Anja Helmerhorst (Managing Editor), PO Box 9600, NL } \\
2300 \text { RC Leiden, The Netherlands or Frans M Helmerhorst } \\
\text { (Co-ordinating Editor), Department of Gynaecology and } \\
\text { Reproductive Medicine, Leiden University Medical Centre, } \\
\text { PO Box 9600, NL } 2300 \text { RC Leiden, The Netherlands }\end{array}$ \\
\hline Helpline: & +31713013182/5262871 \\
\hline Fax: & +31713012822 \\
\hline E-mail: & ahelmerhorst@LUMC.net or F.M.Helmerhorst@LUMC.net \\
\hline Website: & http://fertility-regulation.cochrane.org \\
\hline
\end{tabular}

